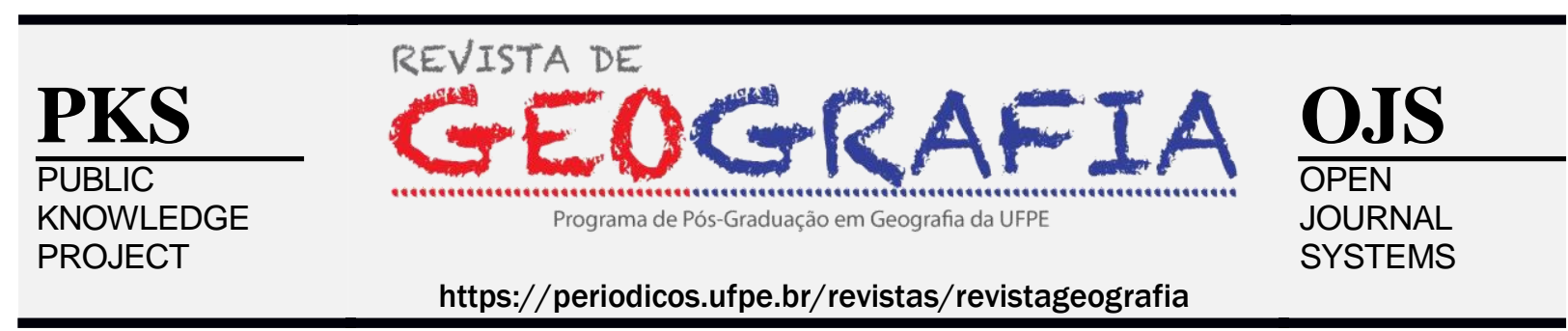

\title{
DIREÇÃO E VELOCIDADE DO VENTO EM JI-PARANÁ E OURO PRETO DO OESTE NO ESTADO DE RONDÔNIA, AMAZÔNIA
}

\author{
Ailton Marcolino Liberato ${ }^{1}$ \\ 1 Graduação em Física (2006) pela Fundação Universidade Federal de Rondônia - UNIR, mestrado (2009) $e$ \\ doutorado (2014) em Meteorologia pela Universidade Federal de Campina Grande - UFCG. \\ Artigo recebido em 29/12/2018 e aceito em 23/11/2019

\begin{abstract}
RESUMO
Este trabalho mostra a direção e velocidade do vento durante o período de inverno e verão no sul da Amazônia Ocidental. Nesse estudo foram utilizados dados diários da direção e velocidade dos ventos coletados no período de 10 de maio de 2005 a 26 de dezembro de 2006, na estação meteorológica automática (1052'53"S; 61 $58^{\circ}$ '13"W

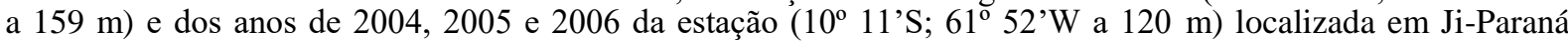
(Rondônia). Também foram utilizados dados do ano de 2004 da estação meteorológica automática $\left(10^{\circ} 45^{\circ} \mathrm{S} ; 62^{\circ}\right.$ $22^{\prime} \mathrm{W}$ a $220 \mathrm{~m}$ ) localizada em Ouro Preto do Oeste (Rondônia). Os resultados mostram velocidades de vento mais frequentes na faixa 0,50 a $2,10 \mathrm{~m} / \mathrm{s}$. Na área de floresta os ventos foram mais intensos de Sul-Sudoeste (período seco) e Norte-Nordeste (período chuvoso). Na área urbana os ventos foram mais intensos de Sudoeste e Nordeste (período seco), Norte-Nordeste (período chuvoso). Em Ouro Preto do Oeste foram observados ventos de SulSudeste (período seco) e Noroeste (período chuvoso). Essas variações podem estar associadas a efeitos locais, como também de aspectos de meso e grande escala da atmosfera.
\end{abstract}

Palavras-chave: Climatologia. Inverno. Verão. Amazônia

\section{WIND SPEED AND DIRECTION IN JI-PARANÁ AND OURO PRETO DO OESTE IN THE STATE OF RONDÔNIA, AMAZÔNIA}

\begin{abstract}
This work shows the direction and speed of the wind during the winter and summer period in southern Western Amazonia. In this study, daily data of the direction and velocity of the winds collected between May 10, 2005 and December 26, 2006, were used in the automatic meteorological station $\left(10^{\circ} 52^{\prime} 53^{\prime \prime} \mathrm{S}, 61^{\circ} 58^{\prime}\right.$ $13^{\prime \prime} \mathrm{W}$ at $\left.159 \mathrm{~m}\right)$ and from the years 2004,2005 and 2006 of the station $\left(10^{\circ} 11^{\prime} \mathrm{S}, 61^{\circ} 52^{\prime} \mathrm{W}\right.$ to $\left.120 \mathrm{~m}\right)$ located in Ji-Paraná (Rondônia). Data from the year 2004 of the automatic meteorological station $\left(10^{\circ} 45^{\prime} \mathrm{S}, 62^{\circ} 22^{\prime} \mathrm{W}\right.$ to $220 \mathrm{~m}$ ) located in Ouro Preto do Oeste (Rondônia) were also used. The results show more frequent wind speeds in the range 0.50 to $2.10 \mathrm{~m} / \mathrm{s}$. In the forest area the winds were more intense South-Southwest (dry period) and North-Northeast (rainy season). In the urban area the winds were more intense of Southwest and Northeast (dry period), North-Northeast (rainy period). In Ouro Preto do Oeste winds were observed from South-Southeast (dry period) and Northwest (rainy season). These variations may be associated to local effects, as well as to meso and large-scale aspects of the atmosphere.
\end{abstract}

Kewords: Climatology. Winter. Summer. Amazon. 


\section{INTRODUÇÃO}

A intensidade da radiação solar incidente à superfície causa as diferenças de temperatura existente na superfície do planeta Terra, e consequentemente, a temperatura causa as diferenças de pressão (FEVROT, 1976).

Sobre uma superfície aquecida as camadas baixas da atmosfera têm tendência a subir, devido o ar quente ser mais leve do que o ar frio. A pressão junto ao solo diminui e forma uma região de baixa pressão (depressão) ou centro ciclônico. Por outro lado, sobre uma superfície fria, o ar desce e torna-se mais denso, a pressão aumenta, formando uma região de alta pressão ou anticiclone (FEVROT, 1976). Logo após, o ar comprimido na região anticiclônica, dirige-se para o vazio relativo criado na região de depressão, e gera o vento. Quanto maior for a diferença de pressão entre os centros ciclônico e anticiclônico, e menor a distância que os separa, maior será a velocidade do vento (FEVROT, 1976).

A direção do vento devia ser em linha reta, do centro de alta pressão para o centro de baixa pressão. No entanto, os ventos são desviados por uma força devido à rotação da Terra em torno do seu eixo (FEVROT, 1976).

A direção e velocidade do vento também sofre influência da topografia e rugosidade da superfície, como também de eventos climáticos extremos (FEVROT, 1976; NOBRE et al., 2011; VIANELLO e ALVES, 2012). A caracterização da velocidade e direção do vento em uma região contribui para melhoraria no planejamento de atividade agrícola, elaboração e execução de projetos de engenharia, geração de energia eólica, orientação para navegação aérea e marítima, prática de esportes náuticos e planejamento ambiental (CAMARGO e SILVA, 2002; DA SILVA, 2007; MARTINS et al., 2008; MUNHOZ e GARCIA, 2008; BRITO-COSTA, 2009; ALVES e SILVA, 2011; COSTA e LYRA, 2012; MASIERO e SOUZA, 2013; MORAIS et al., 2014; SANTOS et al., 2016; ROCKETT et al., 2017).

As mudanças na cobertura vegetal na Amazônia, causadas por ações antrópicas e somadas com a emissão de partículas de aerossóis antropogênicos na atmosfera, pode alterar a composição físico-química da atmosfera (ARTAXO et al., 2005), e consequentemente influenciar a direção e velocidade do vento (IPCC, 2007).

Diante do exposto, este trabalho teve como objetivo analisar a direção e velocidade do vento em Ji-Paraná e Ouro Preto do Oeste no Estado de Rondônia, Amazônia.

\section{METODOLOGIA}

A climatologia da região de Ji-Paraná apresenta temperatura do ar média de $26^{\circ} \mathrm{C}$ e precipitação pluvial anual de $1907 \mathrm{~mm}$. Em seu período seco e chuvoso, a precipitação soma $146 \mathrm{~mm}$ e $1174 \mathrm{~mm}$, respectivamente. Os meses de maio, junho e julho, registra temperatura 
média de $25^{\circ} \mathrm{C}$. E os meses de agosto, setembro, outubro e novembro, apresenta temperatura média de $26^{\circ} \mathrm{C}$ (figura 1).

Figura 1. Climatologia da precipitação e temperatura do ar em Ji-Paraná (RO), entre o período de 1999 e 2010. Dados da Secretaria de Estado do Desenvolvimento Ambiental - SEDAM/RO.

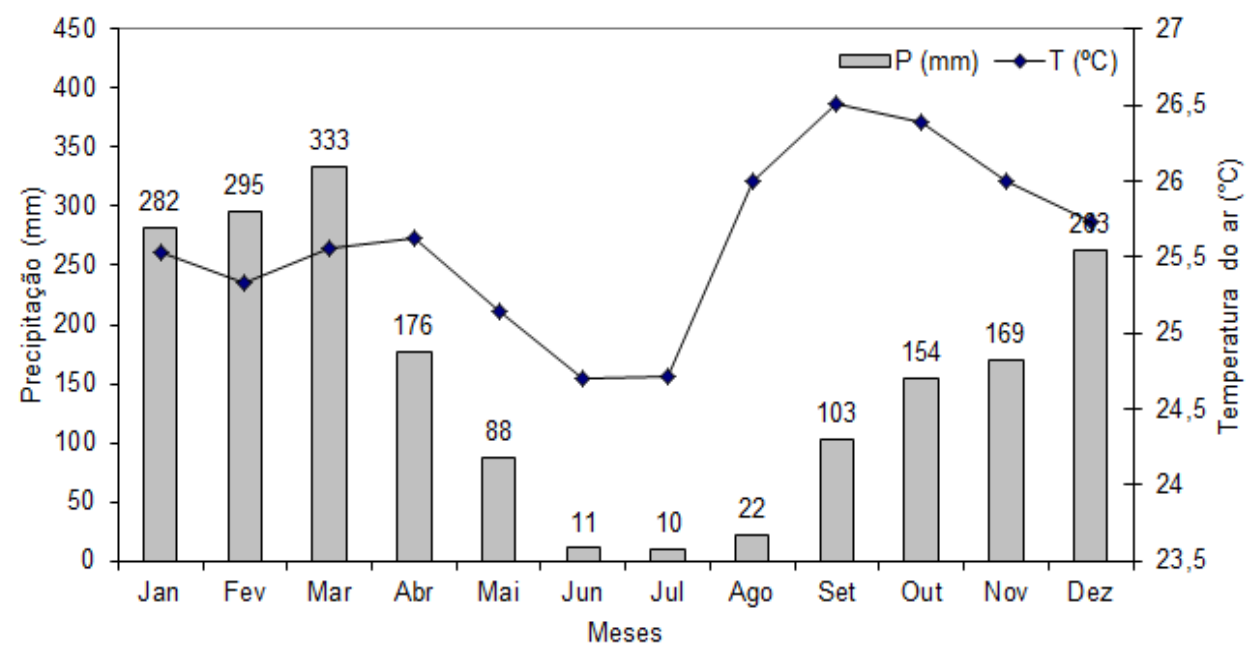

Fonte: elaborado pelo autor.

Segundo estudos realizados no sul da Amazônia Ocidental, a estação seca na região corresponde os meses de junho, julho e agosto (NOBRE et al., 2011). No entanto, Von Randow et al. (2004) registrou o período seco como sendo os meses de julho, agosto e setembro. A estação chuvosa corresponde os meses de dezembro, janeiro e fevereiro (NOBRE et al., 2011). Por outro lado, Von Randow et al. (2004) registrou os meses de janeiro, fevereiro e março, como sendo o período chuvoso.

Nesse estudo foram utilizados dados diários da direção e velocidade dos ventos coletados no período de 10/05/2005 a 26/12/2006, na estação meteorológica automática (1052’53”S; 6158'13”W a 159 m) da Secretaria de Estado do Desenvolvimento Ambiental - SEDAM, em Ji-Paraná, Rondônia (figura 2). Também foram utilizados dados do ano de 2004 da estação meteorológica automática ( $10^{\circ}$ 45'S; 62²2’ W a 220 m) localizada em Ouro Preto do Oeste e dos anos de 2004, 2005 e 2006 da estação (10 11'S; 61 52’W a 120 m) localizada em área de floresta nativa em JiParaná, ambas no Estado de Rondônia (figura 2). Os dados foram coletados por um data logger, de minuto em minuto, e a cada hora, estes dados foram integralizados. Depois de baixados os dados, eles foram organizados e aplicado análise estatística, e em seguida construído gráficos utilizando o software Microsoft Excel e WRPLOT View 8.0.

Figura 2. Localização da área de estudo em Rondônia. Circulo branco (área urbana) e vermelho (área de floresta) em Ji-Paraná e amarelo em Ouro Preto do Oeste. 


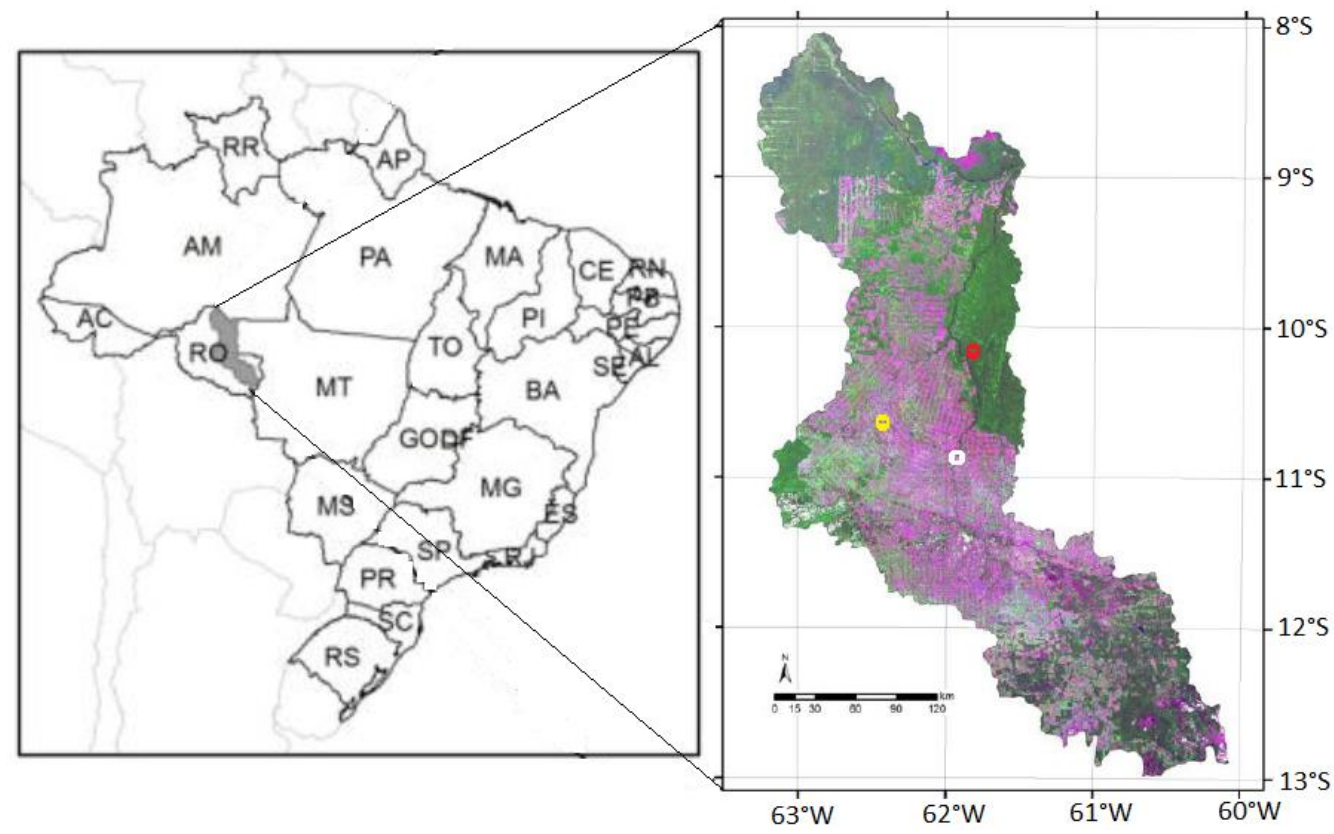

Fonte: adaptado pelo autor de Victoria; Andrade; Paz (2011, p.1).

Foi utilizada a escala criada pelo Almirante da Real Marinha Britânica Sir Francis Beaufort (1774-1857), em 1805, para classificar as faixas de velocidade do vento e relacionar com seus efeitos (tabela 1).

Tabela 1. Escala de vento Beaufort.

\begin{tabular}{|c|c|c|c|}
\hline $\begin{array}{l}\mathbf{N}^{\circ} \\
\text { Beaufort }\end{array}$ & Descrição & Efeitos na terra & $\begin{array}{l}\text { Velocidade } \\
(\mathrm{m} / \mathrm{s})\end{array}$ \\
\hline 0 & Calmaria & A fumaça sobe verticalmente. & $0-0,4$ \\
\hline 1 & Ar leve & $\begin{array}{l}\text { O vento inclina a fumaça, mas } \\
\text { não faz girar o cata-vento. }\end{array}$ & $0,5-1,5$ \\
\hline 2 & Brisa leve & $\begin{array}{l}\text { As folhas se movem e o vento é } \\
\text { sentido no rosto. }\end{array}$ & $1,6-3,4$ \\
\hline 3 & Brisa suave & $\begin{array}{l}\text { As folhas e os ramos pequenos se } \\
\text { movem continuamente }\end{array}$ & $3,5-5,5$ \\
\hline 4 & Brisa moderada & $\begin{array}{l}\text { O vento levanta o pó e as folhas. } \\
\text { Os ramos se agitam. }\end{array}$ & $5,6-8,0$ \\
\hline 5 & Brisa fraca & $\begin{array}{l}\text { Pequenas árvores começam a } \\
\text { balançar. }\end{array}$ & $8,1-10,9$ \\
\hline 6 & Vento forte & $\begin{array}{l}\text { Os ramos grandes se movem. Os } \\
\text { fios elétricos vibram. Dificuldade } \\
\text { em se usar o guarda chuva. }\end{array}$ & $11,4-13,9$ \\
\hline 7 & Temporal moderado & $\begin{array}{l}\text { As árvores se agitam. Há um } \\
\text { incomodo em andar contra o } \\
\text { vento. }\end{array}$ & $14,1-16,9$ \\
\hline 8 & Temporal & $\begin{array}{l}\text { Rompem-se os ramos pequenos } \\
\text { das árvores. Difícil andar contra o } \\
\text { vento. }\end{array}$ & $17,4-20,4$ \\
\hline
\end{tabular}




\begin{tabular}{|c|c|c|c|}
\hline 9 & Temporal forte & $\begin{array}{l}\text { Os ramos médios das árvores se } \\
\text { quebram. }\end{array}$ & $20,5-23,9$ \\
\hline 10 & $\begin{array}{l}\text { Temporal } \\
\text { forte }\end{array}$ & $\begin{array}{l}\text { As árvores são arrancadas e danos } \\
\text { são espalhados. }\end{array}$ & $24,4-28,0$ \\
\hline 11 & Tempestade & $\begin{array}{ll}\text { Destroços extensos. } & \text { Tetos } \\
\text { arrancados, etc. } & \end{array}$ & $28,4-32,5$ \\
\hline 12 & Furação & Produz efeitos devastadores. & $32,6-60,0$ \\
\hline
\end{tabular}

\section{RESULTADOS E DISCUSSÃO}

Foram observados durante o período seco, ventos de Este-Nordeste, Nordeste, NorteNordeste, Sul, Sul-Sudoeste e Oeste-Sudoeste (figura 3a). A velocidade do vento variou entre 0,50 a $2,10 \mathrm{~m} / \mathrm{s}(57,3 \%), 2,10$ a $3,60 \mathrm{~m} / \mathrm{s}(24,1 \%), 3,60$ a $5,70 \mathrm{~m} / \mathrm{s}(7 \%), 5,70$ a $8,80 \mathrm{~m} / \mathrm{s}(0,3 \%)$, sendo registrados $11,2 \%$ dos ventos na classe calmo (figura $3 \mathrm{c}$ ). A figura $3 \mathrm{~b}$ apresenta a direção predominante do vento de Sul-Sudoeste, Oeste-Noroeste e Noroeste na área de floresta nativa. A velocidade do vento variou entre 0,50 a 2,10 m/s (45,9\%), 2,10 a 3,60 m/s (26,9\%), 3,60 a $5,70 \mathrm{~m} / \mathrm{s}(5,4 \%), 5,70$ a $8,80 \mathrm{~m} / \mathrm{s}(0,4 \%)$, sendo registrados $21,4 \%$ dos ventos na classe calmo (figura $3 \mathrm{~d}$ ).

Figura 3. Velocidade e direção do vento em áreas de floresta nativa (b) e urbana (a) no município de Ji-Paraná (RO), com as respectivas distribuições de frequência (d) e (c), durante o período seco dos anos de 2004 a 2006.

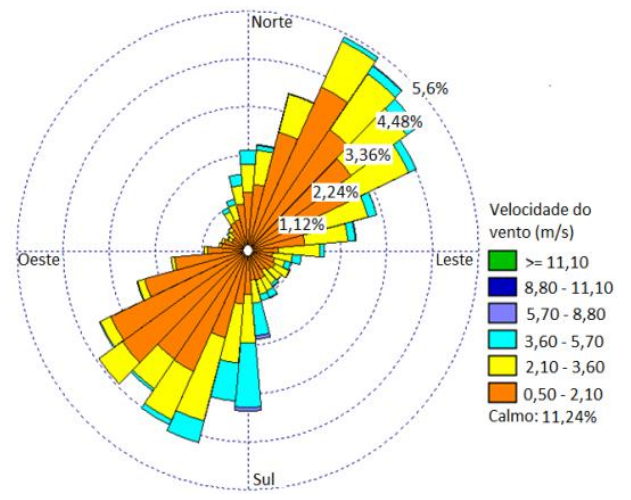

(a)

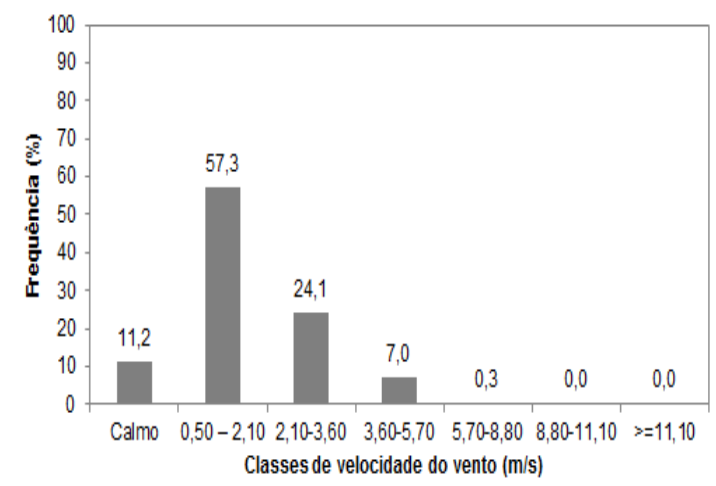

(c)

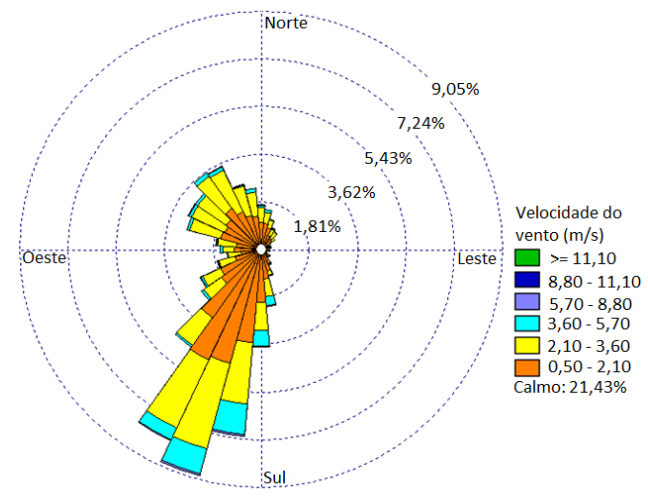

(b)

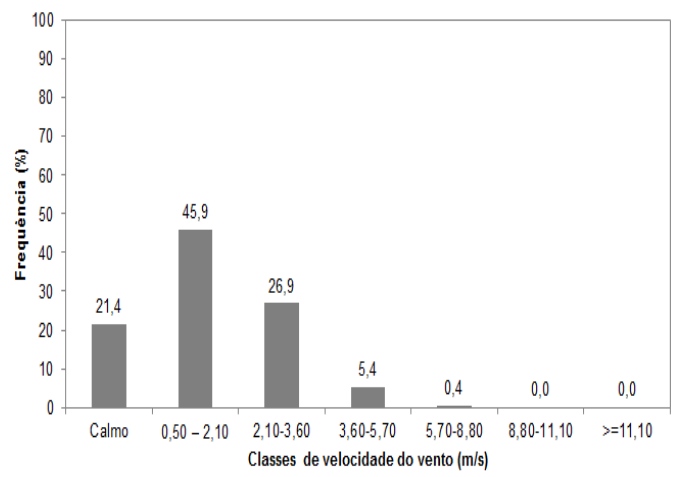

(d) 
Fonte: elaborado pelo autor.

No período chuvoso foram observados ventos de Nordeste, Norte-Nordeste (mais intenso), Norte, Norte-Noroeste e Noroeste (figura 4a). A velocidade do vento variou entre 0,50 a $2,10 \mathrm{~m} / \mathrm{s}(66,4 \%), 2,10$ a $3,60 \mathrm{~m} / \mathrm{s}(21,8 \%), 3,60$ a $5,70 \mathrm{~m} / \mathrm{s}(4,4 \%), 5,7$ a $8,8 \mathrm{~m} / \mathrm{s}(0,1 \%)$, sendo registrados 7,3\% dos ventos na classe calmo (figura $4 c$ ). A figura $4 \mathrm{~b}$ apresenta a direção predominante do vento de Nordeste, Norte-Nordeste (mais intenso), Norte, Norte-Noroeste e Noroeste na área de floresta nativa. A velocidade do vento variou entre 0,50 a 2,10 m/s $(41,4 \%)$, 2,10 a $3,60 \mathrm{~m} / \mathrm{s}(22,5 \%), 3,60$ a $5,70 \mathrm{~m} / \mathrm{s}(4,4 \%), 5,70$ a $8,80 \mathrm{~m} / \mathrm{s}(0,3 \%)$, sendo registrados $18,1 \%$ dos ventos na classe calmo (figura $4 \mathrm{~d}$ ).

Figura 4. Velocidade e direção do vento em áreas de floresta nativa (b) e urbana (a) no município de Ji-Paraná (RO), com as respectivas distribuições de frequência (d) e (c), durante o período chuvoso dos anos de 2004 a 2006.

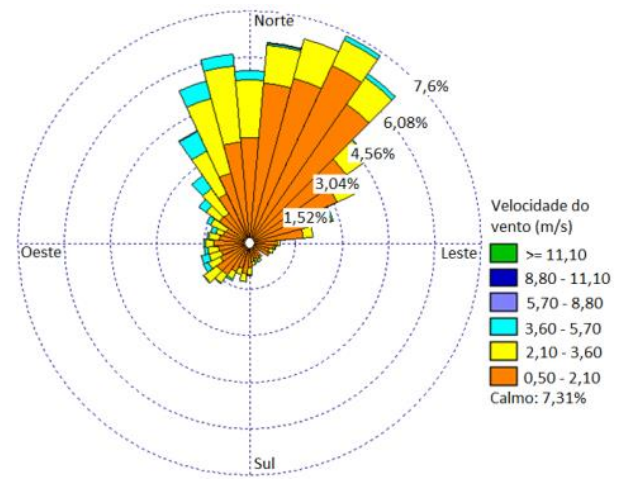

(a)

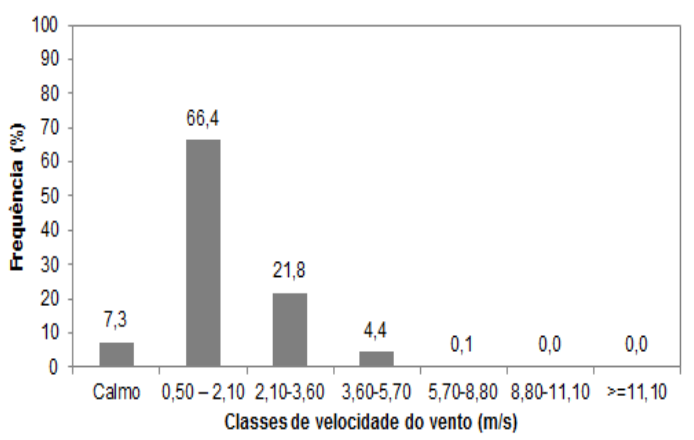

(c)

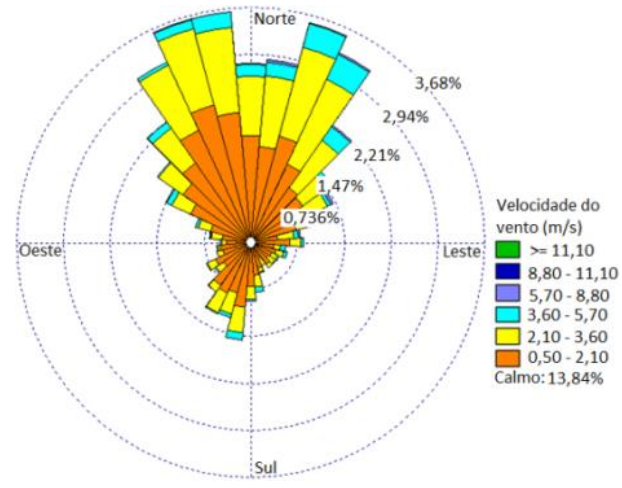

(b)

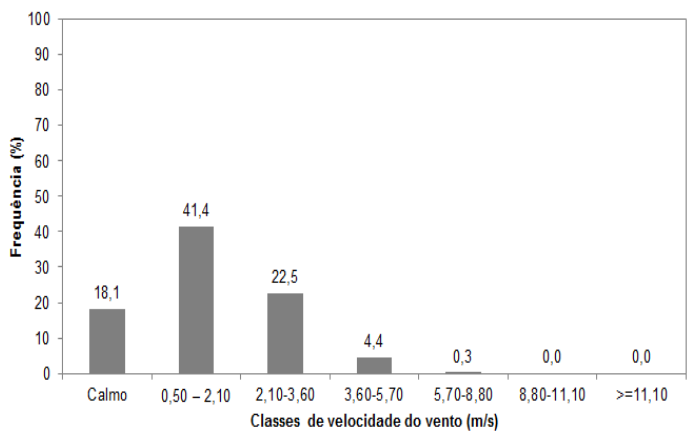

(d)

Fonte: elaborado pelo autor.

Foram observados ventos de Sul, Sul-Sudoeste, Sudoeste, Oeste-Sudoeste, Nordeste, Norte-Nordeste (mais intenso), Norte e Norte-Noroeste (figura 5a) na área urbana, referente à média anual. A velocidade do vento variou entre 0,50 a 2,10 m/s (62\%), 2,10 a 3,60 m/s (23\%), 3,60 a $5,70 \mathrm{~m} / \mathrm{s}(5,4 \%), 5,7$ a $8,8 \mathrm{~m} / \mathrm{s}(0,2 \%)$, sendo registrados $9,4 \%$ dos ventos na classe calmo (figura 5c). A figura 5b apresenta a direção predominante do vento de Sudoeste, Sul-Sudoeste, Sul, Nordeste, Norte-Nordeste, Norte, Norte-Noroeste, Noroeste (mais intenso) e Oeste$\frac{\text { Noroeste na área de floresta nativa. A velocidade do vento variou entre } 0,50 \mathrm{a} 2,10 \mathrm{~m} / \mathrm{s}(41,4 \%)}{\text { Liberato, } 2019 .}$ 
2,10 a $3,60 \mathrm{~m} / \mathrm{s}(22,5 \%), 3,60$ a $5,70 \mathrm{~m} / \mathrm{s}(4,4 \%), 5,70$ a $8,80 \mathrm{~m} / \mathrm{s}(0,3 \%)$, sendo registrados $18,1 \%$ dos ventos na classe calmo (figura $5 \mathrm{~d}$ ).

Figura 5. Velocidade e direção do vento em áreas de floresta nativa (b) e urbana (a) no município de Ji-Paraná (RO), com as respectivas distribuições de frequência (d) e (c), entre 2004 e 2006.

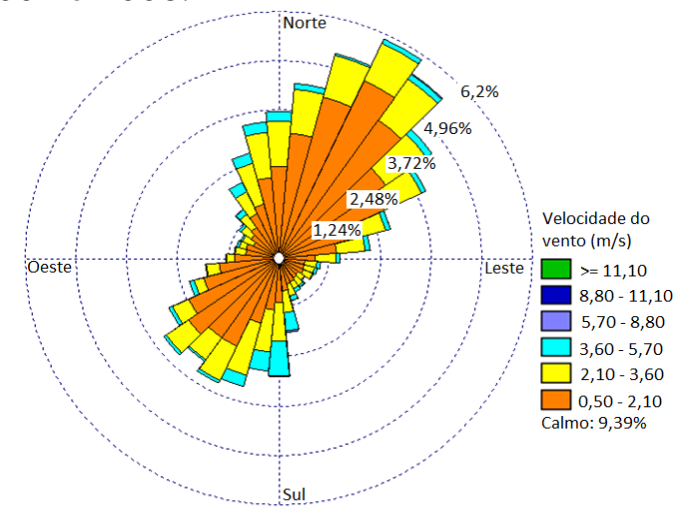

(a)

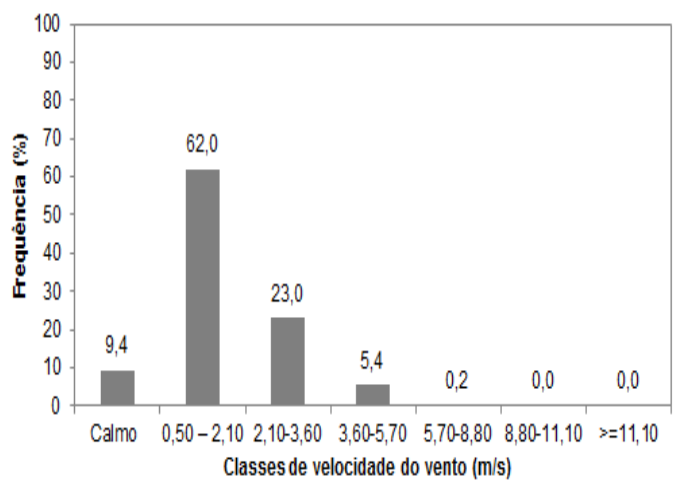

(c)

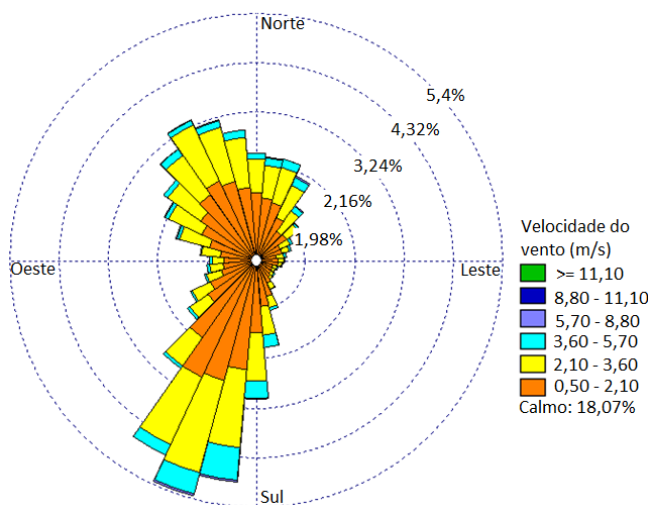

(b)

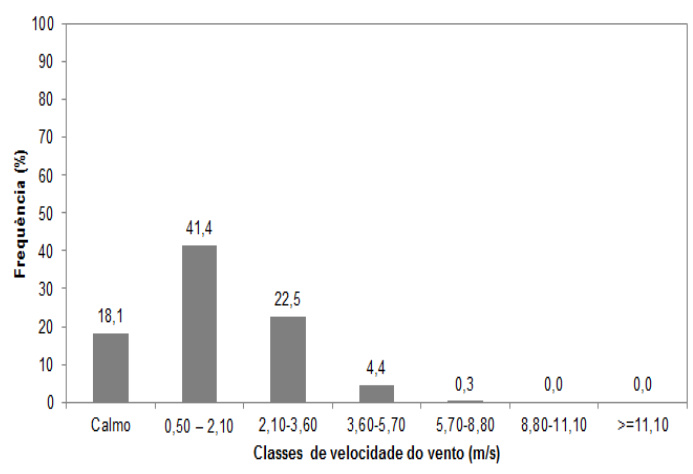

(d)

Fonte: elaborado pelo autor.

No município de Ouro Preto do Oeste foram observados ventos de Norte, NorteNoroeste e Noroeste (figura 6a) no período chuvoso. A velocidade do vento variou entre 0,50 a $2,10 \mathrm{~m} / \mathrm{s}(50,2 \%), 2,10$ a $3,60 \mathrm{~m} / \mathrm{s}(27,7 \%), 3,60$ a $5,70 \mathrm{~m} / \mathrm{s}(15,2 \%), 5,7$ a $8,8 \mathrm{~m} / \mathrm{s}(1,8 \%)$, sendo registrados $5,1 \%$ dos ventos na classe calmo (figura $6 \mathrm{c}$ ). A figura $6 \mathrm{~b}$ apresenta a direção predominante do vento de Sul-Sudoeste, Sul, Sul-Sudeste, Nordeste, Norte e Norte-Noroeste no período seco. A velocidade do vento variou entre 0,50 a 2,10 m/s $(48,5 \%), 2,10$ a 3,60 m/s $(22,4 \%), 3,60$ a $5,70 \mathrm{~m} / \mathrm{s}(12,8 \%), 5,7$ a $8,8 \mathrm{~m} / \mathrm{s}(2,4 \%)$, sendo registrados $0,1 \%$ dos ventos na classe calmo (figura 6d).

Figura 6. Velocidade e direção do vento durante o período chuvoso (a, c) e seco (b, d) em Ouro Preto do Oeste (RO), com as respectivas distribuições de frequência (c), (d) em 2004. 


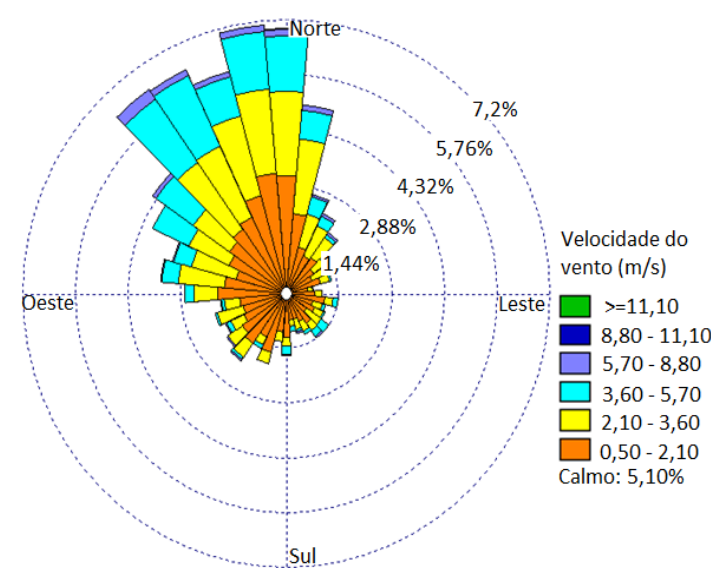

(a)

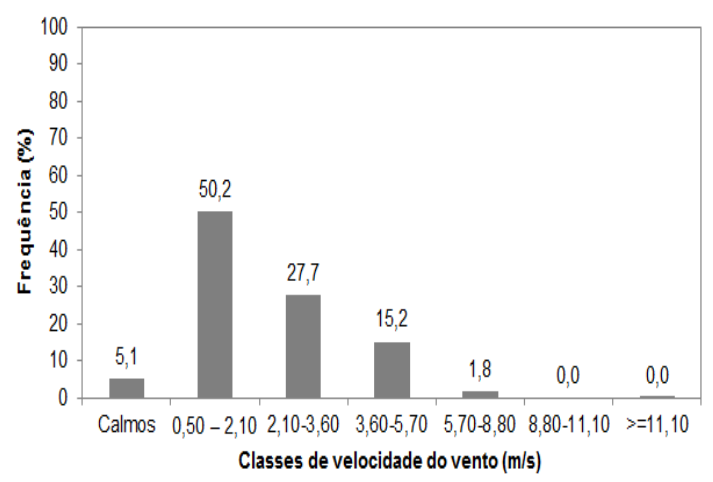

(c)

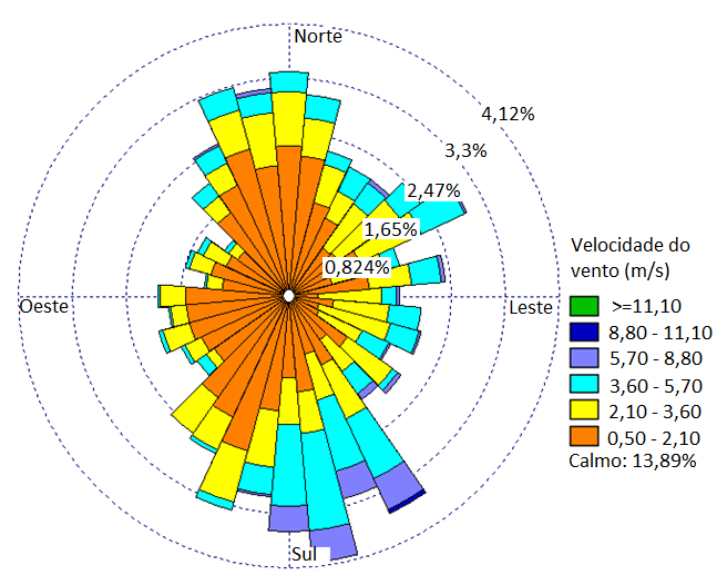

(b)

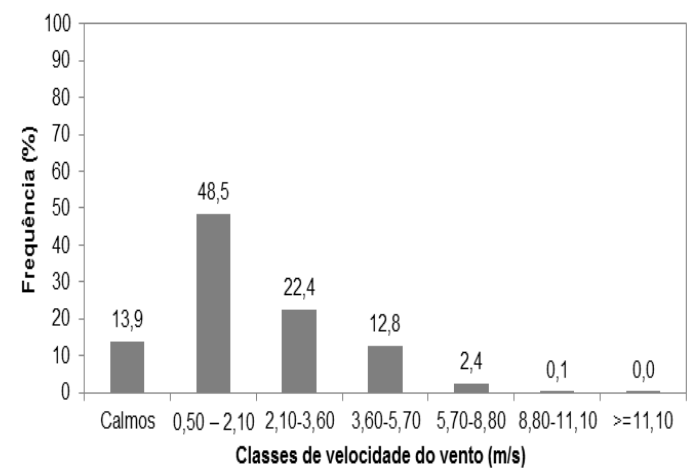

(d)

Fonte: elaborado pelo autor.

Foram observados ventos de Sul, Norte, Norte-Noroeste e Noroeste (figura 7a) em Ouro Preto do Oeste no ano de 2004. A velocidade do vento variou entre 0,50 a 2,10 m/s $(49,4 \%)$, 2,10 a $3,60 \mathrm{~m} / \mathrm{s}(26,2 \%), 3,60$ a $5,70 \mathrm{~m} / \mathrm{s}(14,2 \%), 5,7$ a $8,8 \mathrm{~m} / \mathrm{s}(2 \%)$, e 8,8 a $11,1 \mathrm{~m} / \mathrm{s}(0,1 \%)$ sendo registrados $8,1 \%$ dos ventos na classe calmo (figura $7 \mathrm{~b}$ ).

Figura 7. Velocidade e direção do vento durante o ano de 2004 (a) e distribuição de frequência (b) em Ouro Preto do Oeste, Rondônia.
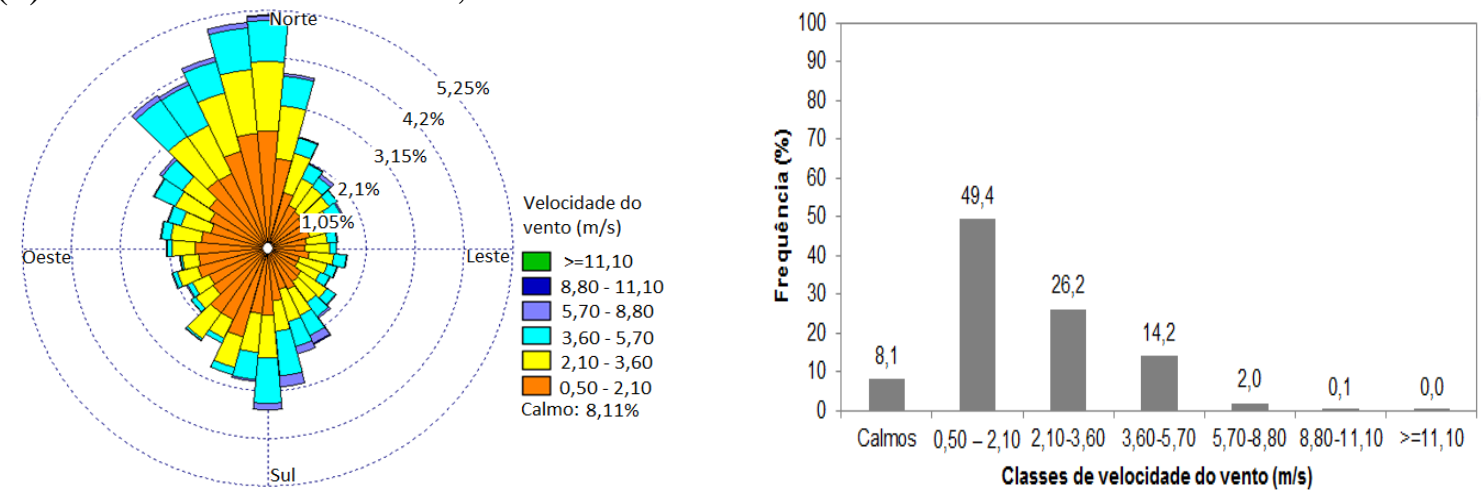

Fonte: elaborado pelo autor.

Durante o período estudado foram observados ventos de calmaria, ar leve, brisa leve, brisa suave, brisa moderada e brisa fraca, segundo a escala Beaufort. As características distintas 
observadas na frequência e na direção predominante do vento na região, durante o período seco e chuvoso, e com relação à média anual, podem estar associadas a linha de instabilidade, brisa fluvial, teleconexões com El-Niño ou La-Niña, interação com sistemas frontais no sul do Brasil, friagem, variabilidade do clima nas escalas interanuais e de longo prazo (FISCH et al., 1998; OLIVEIRA et al., 2004; NOBRE et al., 2011). Além do desflorestamento, mudança no uso da terra, queimadas, aquecimento anômalo do oceano Atlântico, como também os fenômenos blowdowns e downbursts, que são perturbações atmosféricas que ocorrem na Amazônia (ARAUJO et al., 2017).

\section{CONCLUSÃO}

Os resultados mostram velocidades de vento mais frequentes na faixa 0,50 a 2,10 m/s. $\mathrm{Na}$ área de floresta os ventos foram mais intensos de Sul-Sudoeste (período seco) e NorteNordeste (período chuvoso). Na área urbana os ventos foram mais intensos de Sudoeste e Nordeste (período seco), Norte-Nordeste (período chuvoso). E em Ouro Preto do Oeste foram observados ventos de Sul-Sudeste (período seco) e Noroeste (período chuvoso). Essas variações podem estar associadas a efeitos locais, como também de aspectos de meso e grande escala da atmosfera. $\mathrm{O}$ estudo para identificar as características do vento em uma região contribui para um melhor planejamento e uso dos recursos na área urbana e rural do município e em seus diversos setores. Com projetos de urbanização e infraestrutura eficientes, é possível conciliar de forma harmônica a relação homem/natureza com sustentabilidade.

\section{REFERÊNCIAS}

ALVES, E. D. L.; SILVA, S. T. Direção e velocidade do vento em uma floresta de transição Amazônia-Cerrado no norte de Mato Grosso, Brasil. Boletim Goiano de Geografia, v.31, n.1, p. 63 - 74, 2011.

ARTAXO, P.; GATTI, L. V.; LEAL, A. M. C.; LONGO, K. M.; FREITAS, S. R.; LARA, L. L.; PAULIQUEVIS, T. M.; PROCÓPIO, A. S.; RIZZO, L. V. Química atmosférica na Amazônia: a floresta e as emissões de queimadas controlando a composição da atmosfera amazônica. Acta Amazonica, v.35, n.2, p.185-196, 2005.

ARAUJO, R. F.; Nelson, B. W.; CELES, C. H. S.; Chambers, J. Q. Regional distribution of large blowdown patches across Amazonia in 2005 caused by a single convective squall line. Geophysical Research Letters, v.44, n.15, p. 7793 - 7798, 2017.

BRITO-COSTA, G. Análise espacial e temporal do vento no Estado de Alagoas. 2009. $126 f$. Dissertação (Mestrado em Meteorologia), Instituto de Ciências Atmosféricas, Universidade Federal de Alagoas, Maceió - AL. 2009.

CAMARGO, O. A.; SILVA, F. J. L. ATLAS EÓliCO: Rio Grande do Sul. Porto Alegre, SEMC-Secretaria de Energia Minas e Comunicações. 2002. 70 p.

COSTA, G. B.; LYRA, R. F. F. Análise dos padrões de vento no estado de Alagoas. Revista Brasileira de Meteorologia, v. 27, n.1, p. 31-38, 2012. 
DA SILVA, J. K. A. Caracterização do vento e estimativa do potencial eólico da região de tabuleiros costeiros (Pilar, Alagoas). 2007. 79f. Dissertação (Mestrado em Meteorologia), Instituto de Ciências Atmosféricas, Universidade Federal de Alagoas, Maceió - AL. 2007.

FEVROT, Ch. Meteorologia. Coimbra - Portugal: Livraria Almeida, 1976. 92p

FISCH, G.; MARENGO, J. A.; NOBRE, C. A. Uma revisão geral sobre o clima da Amazônia. Acta Amazonica, v. 28, n.2, p. 101 - 126, 1998.

IPCC - Intergovernmental Panel on Climate Change. Climate Change 2007: The Physical Science Basis, Summary for Policymakers. IPCC, Genebra, 2007.

MARTINS, F. R.; GUARNIERI, R. A.; PEREIRA, E. B. O aproveitamento da energia eólica. Revista Brasileira de Ensino de Física, São Paulo, v.30, n.1, p.1304(1)-1304(13), 2008.

MASIERO, E.; SOUZA, L. C. L. Variação de umidade absoluta e temperatura do ar intraurbano nos arredores de um corpo d'água. Ambiente Construído, Porto Alegre, v.13, n.4, p.25-39, jul./set. 2013.

MUNHOZ, F. C.; GARCIA, A. Caracterização da velocidade e direção predominante dos ventos para a localidade de Ituverava-SP. Revista Brasileira de Meteorologia, v.23, n.1, p. 30-34, 2008.

MORAIS, G. M.; SOBRINHO, J. E.; SANTOS, W. O.; COSTA, D. O.; SILVA, S. T. A.; MANIÇOBA, R. M. Caracterização da velocidade e direção do vento em Mossoró/RN. Revista Brasileira de Geografia Física, v.7, n.4, p. 746-754, 2014.

NOBRE, C. A.; OBREGÓN, G. O.; MARENGO, J. A.; FU, R.; POVEDA, G. Characteristics of Amazonian Climate: Main Features. In: KELLER, M.; BUSTAMANTE, M.; GASH, J.; DIAS, P. S. (Org.). Amazonia and Global Change, Geophysical Monography, AGU, Washington, DC, v.186, p.149-162, 2011.

NOAA - National Oceanic and Atmospheric Administration. Disponível em: <https://www.weather.gov/mfl/beaufort>. Acesso em: 24 ago. 2018.

OLIVEIRA, P. J.; ROCHA, E. J. P.; FISCH, G.; KRUIJT, B.; RIBEIRO, J.B.M. Efeitos de um evento de friagem nas condições meteorológicas na Amazônia: um estudo de caso. Acta Amazonica, v.34, n.4, p.613-619, 2004.

ROCKETT, G. C.; TELLES, P.; BARBOZA, E. G.; GRUBER, N. L. S.; SIMÃO, C. E. Análise espaço-temporal dos ventos no extremo norte da Planície Costeira do Rio Grande do Sul, Brasil. Pesquisas em Geociências, v.44, n. 2, p. 203-219, maio./ago. 2017.

SANTANA, L. V. R. Análise do comportamento da velocidade do vento na região Nordeste do Brasil utilizando dados da ERA-40. 2014. 46f. Dissertação (Mestrado em Biometria e Estatística) - Departamento de Estatística e Informática, Universidade Federal Rural de Pernambuco, Recife, Pernambuco, 2014.

SANTOS, T. C.; CARVAlHO, V. S. B.; REBOITA, M. S. Avaliação da influência das condições meteorológicas em dias com altas concentrações de material particulado na Região Metropolitana do Rio de Janeiro. Engenharia Sanitária Ambiental, v.21, n.2, p.307-313, abr./jun., 2016.

VIANELLO, R. L.; ALVES, A. R. Meteorologia básica e aplicações. 2 ed., rev. ampl., Viçosa - MG: Ed. UFV, 2012. 460p. 
VICTORIA, D. C.; ANDRADE, R. G.; PAZ, A. R. Banco de dados hidrometeorológicos do projeto HidroJipa. Cicular Técnica Embrapa, 16, Campinas, SP, dez. 2011. 12p

VON RANDOW, C.; MANZI, A. O.; KRUIJT, B.; OLIVEIRA, P. J.; ZANCHI, F.B.; SILVA, R. L.; HODNETT, M.; GASH, J.; ELBERS, J. A.; WATERLOO, M.; CARDOSO, F. L.; KABAT, P. Comparative measurements and seasonal variations in energy and carbon exchange over forest and pasture in South West Amazonia. Theoretical and Applied Climatology, v. 78, p. 5-26, 2004. 